\title{
Research on Information Design and Application of Computer Specialties in Higher Vocational School Based on Mobile Learning Environment
}

\author{
Jinrong Zhou ${ }^{1, *}$ Zhen $\mathrm{Hu}^{1}$ Juan Yang ${ }^{1}$ Yuan Liu ${ }^{1}$ \\ ${ }^{1}$ Department of Electronic Information Engineering, Nanchong Vocational and Technical College, Nanchong, \\ Sichuan 637131, China \\ *Corresponding author. Email: 59589266@qq.com.
}

\begin{abstract}
Students' learning is not limited by time and place thanks to mobile learning environment, which facilitates teachers' information-based teaching. However, mobile learning requires high ability and awareness of students' independent learning, especially for the abstract and boring computer specialties in higher vocational school, which dampens information-based teaching effect. In this paper, considering mobile learning environment, careful information-based teaching design and practice concerning computer specialties in higher vocational school are conducted to utilize the application edges of mobile learning, and significantly improve teaching effect.
\end{abstract}

Keywords: Mobile learning, Higher vocational school, Computer, Information-based design.

\section{INTRODUCTION}

The booming network technology and popularization of smart mobile terminals give birth to mobile learning, a new learning method, which is increasingly welcomed by learners and has become a common means for vocational teachers to implement information-based teaching because it's free of the restriction of time and space. However, most information-based teaching conducted by higher vocational teachers is limited to the application of learning APPs and video resources, which undermines the desired effect of information-based teaching. How to implement information-based teaching design in the context of mobile learning environment and fully utilize the application edges of mobile learning matter significantly in terms of the teaching effect of computer specialties in higher vocational school.

*Fund: The research project of Nanchong Vocational and Technical College in 2020: Research on Information Design and Application of Computer Specialties in Higher Vocational School based on Mobile Learning Environment (Project No.: RWB31).

\section{THE CONCEPT OF INSTRUCTIONAL DESIGN AND INFORMATION-BASED TEACHING DESIGN}

\subsection{Instructional Design}

As for the concept of instructional design, the one proposed by Gagne in his book Principles of Instructional Design is more authoritative: "Instructional design refers to the process of systematically planning an instructional system which itself is a learning-friendly arrangement of resources and procedures. Any organization whose purpose is to cultivate people's talents can be included in the system." On this basis, Gagne put forward the five elements of instructional Design (ADDIE model): Analysis, Design, Development, Implementation and Evaluation. The five elements of instructional design, which are widely accepted in China, including teaching object, teaching objective, teaching strategy, teaching process and teaching evaluation, are based on Gagne's insight. 


\subsection{Information-based Teaching Design}

Professor Li Jiahou of Shanghai Normal University first proposed the concept of information-based teaching design. He holds that information-based teaching design is to optimize the teaching process by systematic methods, taking learning as the center, making full use of modern information technology and information resources, and scientifically arranging each link and element of the process. Information-based teaching design mainly covers the following elements: analysis of unit teaching objective and learner characteristics, selection and design of teaching mode and strategy, learning situation and learning task, and teaching media and teaching resources, and design of teaching evaluation.

\section{CURRENT SITUATION OF INFORMATION-BASED TEACHING UNDER MOBILE LEARNING ENVIRONMENT}

May 23, 2015 witnessed the opening of the first International Conference on Information-based Technology in Education in Qingdao. Xi said in his letter of congratulations, given the progress of information technology, education reform and innovation should be promoted to build a networked, digital, personalized and life-long education system. A learning society in which "everyone can learn wherever and whenever" should also be established to cultivate a large number of creative talents. This is a major task facing all mankind. [1] Thanks to the effective implementation of information-based teaching mode in recent years, information-based teaching has been essential for education modernization. However, no desired effect has been made in information-based teaching, which can be explained from the following three aspects.

\subsection{Emphasis on Construction over Application}

Aware of the widespread popularity of information-based teaching, various vocational colleges have invested a lot to strengthen the construction of campus network, cloud computing processor, Internet of Things and other related facilities. As a result, smart campus has gradually become the focus of all colleges and universities. However, most colleges and universities emphasize exclusively on the construction of hardware environment over the development of APPs and teaching resources, never bothering themselves to the actual role of information-based teaching facilities on education.

Software and talent are indispensable. Information-based teaching software "based on data and content" requires teachers' deep application. However, the information construction department and the educational administration department operate separately in many higher vocational colleges, which leads to mismatch: the administrative personnel of the information construction department who do not participate in teaching are proficient in the information-based teaching software, while the teachers in the front line of teaching seldom master the know-how concerning these software.

The lack of professional teaching resources and repeated construction seriously cripple the information-based teaching. Now, higher vocational colleges focus on the construction of their own online teaching resources, which leads to repeated and extra online teaching resources. In addition, these resources lack pertinency, coupled with shortage of quality teaching resources, wasting the human, material and financial resources invested in the construction of teaching resources.

\subsection{Emphasis on Form over Quality}

Thanks to the popularization of smart terminals, mobile learning provides new teaching alternatives for teachers. Based on the rich online teaching resources, many teachers assign learning tasks before class, during class and after class, following the practice of flipped classroom, encouraging students to study in their spare time. But expected effect are seldom reached, which is largely due to teachers' focus on implementation process and their failure to take into account students' existing knowledge, receiving ability and self-learning consciousness.

Teachers in higher vocational colleges are generally equipped with the ability of informationbased teaching, and the following mode is often followed: release learning resources before class, solve students' questions in class, and assign learning tasks after class. Teachers have been conditioned to think that such mode is sure to improve teaching effect, never considering the appropriateness of flipped classroom. Students in higher vocational colleges prefer hands-on practice. They are not patient enough to learn the video resources released by teachers in advance before 
class. They often take a cursory look, which undermines learning effect. Insufficient preparation before class leads to too many questions from students in class, and the limited time in class makes it impossible for teachers to effectively solve all questions. Affected by the first two unsatisfactory links, students are unable to finish the tasks after class with high quality.

\subsection{Emphasis on Data over Feedback}

The existing smart teaching software, like the commonly used rain classroom, MosoInk, Learning to learn, Courses, etc., can record each learning process and generate learning data, such as a student's preview, homework accuracy, participation, etc. Teachers can know exactly how each student is doing through such data analysis. However, most teachers fail to take effective feedback and intervention measures such as adjusting the specific teaching content after understanding the specific situation of students. As a result, data analysis is only regarded as learning results, rather than indicators for regular adjustment and feedback of teaching content.

In fact, data analysis not only helps teachers understand students' learning, but also can be employed to motivate students. These highly traceable data serve as rational teaching analysis, helping teachers to make effective improvement. Many teachers are happy to enjoy the convenience brought by data, but ignore the feedback function of data. Students are also allowed to see their learning effects through smart teaching software. However, it is difficult for students to effectively improve learning without the attention and supervision of teachers in the process.

\section{ANALYSIS OF ELEMENTS OF INFORMATION-BASED TEACHING DESIGN}

\subsection{Analysis of Unit Teaching Objective}

Teaching objectives, direction indicator of teaching activities, is the priority of informationbased teaching design, clearly and specifically describing what learners can gain through teaching. Analysis of unit teaching objective is mainly to determine the learning content or theme of the class, the knowledge and ability that students can master after learning, the learning results, and the emotional attitude and values that students can enhance.
In general, the teaching objectives of a subject are determined before the teaching objectives of the unit. A complete teaching objective should include audience, behavior, condition and degree, which is referred to as ABCD mode. Among them, audience refers to the specific students who need to complete the behavior, such as "Computer Application Technology Class 1, Group 1". Behavior refers to the specific observable behaviors that specific students need to complete in the teaching process, such as "image picking and programming". Condition refers to the restrictions required to complete a specific behavior, such as "using Premiere software or Camtasia Studio software", or while statement in $\mathrm{C}$ language. Degree refers to a measure of completed behavior, such as "ensuring the natural and colorless edge of the portrait, or correctly obtaining the sum of $1+2+3+\ldots+100 "$.

\subsection{Selection and Design of Teaching Mode and Strategy}

Teaching mode refers to the basic program or framework of teaching activities under the guidance of certain teaching theories. Information-based teaching generally adopts the "online" and "offline" blend learning, which integrates the strengths of online teaching and traditional teaching. Students who only follow online learning platforms are prone to issues such as weak self-control, poor course completion rate and unfavorable communication and discussion effect. Students who singly adopt traditional teaching mode featuring dominance of teachers' teaching and passive acceptance of students have difficulty enhancing their thinking, innovation and critical thinking. Blended teaching can effectively complement the defects of online learning and traditional classroom learning. In such mode, the learning process is controlled and supervised by the teacher, and students can discuss and communicate their issues online or offline. In addition, student-centered autonomous learning is promoted, enabling students to enjoy an immersive learning experience that improves their creativity and critical thinking.

In terms of teaching strategies, informationbased teaching advocates such teaching methods as scaffolding instruction, anchored instruction and random access instruction. Anchored instruction requires teachers to provide a real situation, identify a topic, and then use open and comprehensive questions to encourage students to think about the topic from multiple perspectives. The scaffolding instruction first builds the frame scaffolding of the 
problem and introduces the problem with the information paving teaching method. Random access instruction means that students approach the problem from a certain angle and explore around the entity.

\subsection{Design of Learning Situation and Learning Task}

According to constructivist learning theory, effective learning requires the creation of a certain "situation", as "situation" can effectively stimulate students' associative power, allowing students to "assimilate" or "adapt" to the new knowledge they have learned based on relevant knowledge and experience. Therefore, the teaching design under the information-based teaching environment values the creation of learning situation.

Generally, learning situation can be divided into story situation, problem situation, resource situation and virtual experiment situation according to the content presented. In the information environment, the processing of sound, video, animation, hyperlink and so on can transform the content of textbooks into digital learning resources. Such resources can be adopted to create a certain situation, contributing to strengthen the learners' understanding of learning content and improve their learning ability. The design of learning task is closely related to the design of learning situation. Learning task may involve a problem, a case study, or a project. The design should be closely aligned with the knowledge or skills stipulated by the teaching objectives. Learning situation enables students to better understand the task and stimulate their enthusiasm to solve the problem or the real task.

\subsection{Selection and Design of Teaching Media and Teaching Resources}

The selection and design of teaching media and teaching resources under information-based teaching environment mainly refers to the selection of hardware media, software resources, design and development tools. The selection of media in teaching requires careful deliberation based on teaching objectives, teaching contents and learners' characteristics.

Teaching resources, also known as learning resources, are adopted to support students' learning during the learning process. In order to save time, money and effort, readily available resources should be preferred. Redevelopment of resources should be considered when existing resources cannot meet demand. The development of learning resources needs to be combined with teaching conditions, following the steps of topic selection analysis, material preparation, script writing, development, evaluation and modification. In addition to providing students with rich, diversified and appropriate learning resources, the design of information-based teaching environment should also provide students with cognitive tools to help and promote students' absorption of learning resources.

\subsection{Design of Teaching Evaluation}

Teaching evaluation is a process of measuring the process and results of teaching activities based on teaching objectives and making value judgments with scientific standards. The design of teaching evaluation should take into account the following several issues. The first is evaluation content. It mainly refers to the "evaluation of what", which can be determined combining students' performance in class, such as students' words, students' actions, students' cognitive level. The second is the subject of evaluation, mainly to solve the problem of "who will evaluate". The diversity of the subject of evaluation should be valued,

For example, the teacher evaluation can cover teacher's evaluation of the whole class, of some students, of student group and of individual student, while the student evaluation should include students' self-evaluation, mutual evaluation, group mutual evaluation and group cooperation evaluation. Sometimes parental evaluation can be added.

Information-based teaching design generally divides the evaluation into three links: before class, in class and after class. Diagnostic evaluation of students before class generally refers to the prediction of students' knowledge, skills and emotions before the implementation of teaching activities, so as to understand the knowledge foundation and preparation of students and provide a basis for the implementation of course teaching.

Formative evaluation of students in class generally refers to the process of timely modification in order to understand the learning situation of students and obtain continuous feedback, so as to clarify the problems existing in teaching activities. Summative evaluation is conducted after class, generally after the end of a 
unit teaching activity, or after the end of the whole teaching activity.

\section{INFORMATION-BASED DESIGN AND APPLICATION OF COMPUTER SPECIALTIES IN HIGHER VOCATIONAL SCHOOL}

Taking IT Entrepreneurship Case as an example, the classroom teaching is conducted in the form of information-based teaching design.

\subsection{Analysis of Unit Teaching Objective}

\subsubsection{Course Orientation}

IT Entrepreneurship Case, a professional restrictive course for electronic information majors, mainly helps college students to understand and master relevant knowledge and rules of IT industry innovation and entrepreneurship, aiming to actively implement the national policy on deepening innovation and entrepreneurship education for college students, and improve college students' innovation consciousness and entrepreneurial ability. The textbook of "the first batch of innovation and entrepreneurship education model courses" was adopted. The course is composed of five modules. The IT entrepreneurship case belongs to the fourth module, including case description and case analysis. This hour period is 6 hours in total.

\subsubsection{Analysis of Learning Subjects}

This teaching design is available for students majoring in electronic information engineering and technology of grade 2018. There are 25 male students and 2 female students in this class.

The general characteristics of students: male students account for the vast majority, and are more enthusiastic about entrepreneurship than female students. They enjoy flexible thinking, the courage to innovate, the gut to break the rules, a strong sense of self and independent personality.

The initial ability of the students: the basic knowledge of IT entrepreneurship hot spot, entrepreneurship preparation and so on.

The learning style of students: highly interested in practical tasks and information learning, and prefer learning in groups.

\subsubsection{Course Objectives}

Knowledge objective is to learn from others' entrepreneurial experience and practices through case study and analysis.

Skill objective is to improve students' market insight, analysis and implementation through interviews and communication with people.

Quality objective is to stimulate students' interest and enthusiasm in entrepreneurship and enhance their communication and cooperation ability by implementing tasks in groups.

\subsection{Selection and Design of Teaching Mode and Strategy}

Flipped classroom is adopted in combination with the nature and characteristics of teaching content. The project-oriented learning method and the interactive learning platform of rain classroom are utilized to integrate micro-classes, MOOCs, online model courses, digital teaching resources of sand table simulation software, digital textbooks and platforms. The general manager of Zhiyong Technology Co., Ltd., outstanding entrepreneurial college students (now CEO of Chuying Network Technology Co., Ltd.) and experts from research institute of electronic information industry were also invited to provide guidance, connecting online and offline, and realizing mobile learning and mixed learning.

\subsection{Design of Learning Situation and Learning Task}

The first is to utilize the interactive learning platform of rain classroom to stimulate students' interest and enthusiasm in learning. Teachers can send IT business cases, assign project assignments, publish online test questions, etc. Students can learn IT business cases, communicate and discuss questions in the learning process through the platform, or seek help from experts online, and complete teaching tests and assessments as required.

The second is to set up a team of experts to provide guidance and help for students to learn the case and complete the writing of the project assignment.

Student representatives' interview with the general manager of Zhiyong Technology Co., Ltd., the exchange and interaction in the discussion area of rain classroom with outstanding entrepreneurial 
college students, and the on-site Q\&A by experts of research institute of electronic information industry help students to summarize experience through the case and complete the project tasks.

Finally, teaching objectives can be completed in the whole process. Online and offline thoroughly connect, truly realizing mobile learning and blend learning.

\subsection{Selection and Design of Teaching Media and Teaching Resources}

Digital teaching resources such as microcourses, MOOCs, animations, online quality courses, and sand table simulation software are integrated to enable students to deeply understand and evaluate cases, improve students' independent learning and analysis, and accumulate knowledge and experience for the writing of follow-up project assignments.

\subsection{Design of Teaching Evaluation}

The teaching evaluation of this lesson is divided into diagnostic evaluation, formative evaluation and summative evaluation. Among them, diagnostic evaluation is the pre-class evaluation, which mainly predicts and analyzes the entrepreneurial foundation of students through the basic knowledge test of entrepreneurship. Formative evaluation is an online evaluation conducted on students in class. Through classroom learning, answering questions and summarizing, students are tested on the knowledge elements of entrepreneurial success, so as to understand their mastery of knowledge and further promote teaching. After class, summative evaluation is conducted, mainly voting on group performance, including self-evaluation, mutual evaluation and teacher evaluation.

\subsection{Implementation Effect and Improvement Measures of Teaching}

Information-based teaching, as a new thing, enables vocational college students who generally own tablets or mobile phones to break away from tablets and mobile phone games and study in their spare time, which is helpful to significantly improve classroom efficiency and students' learning initiative.

However, there are flaws in its practice. Some students are not familiar with smart learning software, some use Baidu to search for answers, group collaboration is more of a form, etc., which concerns information-based teaching design.

The information-based teaching design in the mobile environment should be explored, summarized and reflected repeatedly from the aspects of teachers, students and smart teaching software.

First, teachers should emancipate their minds, establish information-based teaching concepts, and embrace information-based teaching methods. Secondly, students should be actively guided to participate in information-based teaching, cooperate in groups, and strengthen online and offline communication. Finally, the smart teaching software should be easy to operate. Pre-class training is preferable to enable students to master such software.

\section{CONCLUSION}

The expansion on enrollment of higher vocational colleges brings about public attention to its teaching quality. Course construction based on network teaching platform serves as an important means of information-based teaching. The instructional design of network course is the guarantee of information-based teaching. Information-based teaching design and practice under the mobile learning environment gives full play to the application edges of mobile learning and effectively improve teaching effect.

\section{AUTHORS' CONTRIBUTIONS}

Jinrong Zhou is Responsible for the planning of the project, this paper is mainly completed by Jinrong Zhou, Zhen Hu is responsible for the course design, Juan Yang is responsible for the course implementation, and Yuan Liu is responsible for the course evaluation.

\section{REFERENCES}

[1] http://politics.people.com.cn/n/2015/0524/c10 24-27046494.html

[2] Diao Junfeng, Han Xibin, Zhang Yi. Strategy Analysis of Teachers' ICT Competence Training during COVID-19: Based on Cases from 28 Vocational Colleges [J]. E-education Research, 2021, 42(01): 115-121. (in Chinese)

[3] $\mathrm{Hu}$ Huiying. Database Technology and Application Course Teaching Design based on Information Technology [J]. Journal of Wuhan 
Institute of Shipbuilding Technology, 2020, 19(04): 53-56. (in Chinese)

[4] Luo Li. Discussion on teaching design under the background of higher vocational education curriculum information [J]. Yangtze River Series, 2020(28): 94-95. (in Chinese)

[5] Yang Qian. Research on the Informationbased Teaching Design of the $\mathrm{C}$ Language Course in Higher Vocational Education [J]. The Science Education Article Collects, 2020(05): 80-81. (in Chinese)

[6] Yinqin. Practical research and exploration of teaching design of higher vocational curriculum information [J]. Journal of Higher Education, 2020(12):118-123. (in Chinese)

[7] Wang Dandan, Zhao Wenyong, Zhao Xuehua. Research on the Teaching Reform of Informationized Tertiary Vocational Education Courses in Internet+ Age $[\mathrm{J}]$. Modern Computer. 2019(15): 60-64. (in Chinese) 